\title{
INTERPRETAÇÃO E TEORIA NAS CIÊNCIAS \\ NATURAIS \\ E NAS CIÊNCIAS HUMANAS: COMENTÁRIOS A RESPEITO DE KUHN E TAYLOR ${ }^{1}$
}

Hugh LACEY ${ }^{2}$

- RESUMO: O objetivo do artigo é o de extrair dos escritos de Taylor uma crítica da concepção de Kuhn a respeito de uma possível unidade entre as ciências naturais e as ciências humanas, e dos de Kuhn uma crítica à caracterização proposta por Taylor para as ciências naturais. Deste empreendimento resulta uma reconceptualização da unidade das ciências.

- PALAVRAS-CHAVE: Unidade da ciência; entendimento; fisicalismo; controle tecnológico; valores epistêmicos.

\section{Teoria e interpretação}

As práticas científicas visam produzir entendimento, o qual consiste freqüentemente em descrições das leis e estruturas subjacentes aos vários fenômenos. As teorias científicas articulam tais descrições. As práticas científicas modernas têm tido extraordinário sucesso em produzir teorias, muitas das quais consideradas bem confirmadas, pelo menos aproximadamente, para domínios específicos ou sob certas condições de contorno. Em virtude de seu sucesso a ciência natural moderna adquiriu

\footnotetext{
1 Artigo originalmente publicado no periódico Journal for the Theory of Social Behavior, v.20, p.197-212, 1990. Tradução de Marcos Barbosa Oliveira e Isabel Maria Loureiro, respectivamente, Departamento de Filosofia da Educação e Ciências da Educação - Faculdade de Educação - USP 05508-900 - São Paulo - SP, e Departamento de Filosofia - Faculdade de Filosofia e Ciências UNESP - 17525-900 - Marília - SP - Brasil.

2 Departamento de Filosofia - Swarthmore College, Swarthmore - Pennsylvania - EUA.
} 
um tipo de autoridade tal que muitos a vêem como uma prática cognitiva exemplar, o paradigma da racionalidade, legitimando assim seu avanço imperialista sobre outros domínios, inclusive o dos fenômenos humanos. E, com efeito, práticas visando entender o comportamento humano, as capacidades cognitivas humanas e as relações sociais em termos de sua geração pelas estruturas e leis subjacentes se multiplicaram durante este século.

As teorias científicas carregam essencialmente a marca da história, assim como acontece com as práticas que as produzem, mantêm, modificam, transformam e substituem. Thomas Kuhn, entre outros, é responsável por este ponto de vista ter se tornado praticamente um lugar-comum. Não surpreendentemente, o argumento de Kuhn é extraído de uma leitura da história da ciência, da qual um componente básico envolve uma atividade interpretativa que repõe a ciência passada no contexto de sua própria matriz disciplinar e de seu léxico estruturado.

A atividade interpretativa parece desafiar uma explicação em termos de comportamentos regidos por leis ou de ações governadas por regras e portanto resistir à incorporação ao modo de entendimento fornecido pela teoria científica. A partir disso pode-se rapidamente concluir que esforços para entender as práticas da ciência imporiam limites razoavelmente claros para o avanço imperialista da teoria científica, que as concepções fisicalistas e positivistas da unidade da ciência ruiriam perante as próprias práticas da ciência. Além disso, uma vez que a atividade interpretativa (e, mais geralmente, intencional) tanto constitui o objeto das ciências humanas quanto representa um papel importante em suas investigações, parece decorrer (como Charles Taylor vigorosamente argumenta) que haveria uma falta de unidade fundamental e de princípio entre as ciências naturais e humanas. Kuhn, entretanto, não extrai tais conclusões.

Em vez disso, Kuhn fez duas sugestões complementares. Primeiro, tira implicações para o presente de sua leitura da história da ciência. Todas as avaliações de teorias científicas, inclusive as teorias contemporâneas mais bem estabelecidas, são feitas contra o pano de fundo da matriz disciplinar e a construção da teoria é restringida por um léxico estruturado. A inteligibilidade da teoria se apóia em um pano de fundo compartilhado ao qual o acesso explícito só pode ser obtido por meio da interpretação. A interpretação, portanto, não é exclusividade das ciências humanas; talvez tenha nelas um papel explícito que é apenas implícito nas ciências naturais. Em segundo lugar, Kuhn sugere que pode haver apenas um lapso de tempo entre as ciências humanas e as naturais no que se refere à expressão do entendimento sob forma teórica. É assim que leio suas numerosas observações sobre o estado "pré-paradigmático" das ciências sociais. Elas podem tornar-se paradigmáticas, isto é, a prática em 
qualquer uma delas pode ser enquadrada por uma matriz disciplinar particular e por um léxico estruturado a partir do que a teoria (a qual, neste artigo, é usada no sentido de representações sistemáticas de regularidades, leis e estrutura) torna-se inteligível, é gerada, mantida e reformada. Continua, sendo verdade que o acesso explícito a tal enquadramento se daria apenas por meio da interpretação, porém isto não constitui uma razão para Kuhn suspeitar de qualquer tentativa de produzir teoria nas ciências humanas. Para ele a aplicabilidade de qualquer teoria tem limites. Sustenta que não há teoria abrangente alguma, e que teoria alguma oferece entendimento de sua própria matriz disciplinar. Isto não implica entretanto que não possa haver teorias que nos permitam resolver quebra-cabeças, produzir explicações e fazer predições concernentes a agregados consideráveis de comportamentos humanos e sociais. Essas duas sugestões não encorajam versões fisicalistas-positivistas da unidade da ciência, mas também deixam como uma questão em aberto se existe uma falta de unidade de princípio entre as ciências naturais e as ciências humanas. O próprio Kuhn se satisfaz permanecendo agnóstico sobre a questão.

Taylor não aceita nem as versões fisicalistas-positivistas da unidade entre as ciências naturais e as ciências humanas nem a sugestão de Kuhn da sua possível unidade. Ele não nega que toda pesquisa científica seja enquadrada por uma matriz disciplinar à qual o acesso explícito deriva de interpretação. Apesar disso diverge de Kuhn na caracterização, tanto das ciências naturais quanto das humanas. Ele está mais próximo do que Kuhn das caracterizações fisicalistas das ciências naturais, e vê a teoria como incapaz de oferecer entendimento significativo da vida e ação humanas.

Este artigo tem o objetivo limitado de extrair dos escritos de Taylor uma crítica correta à sugestão de Kuhn sobre a possível unidade entre as ciências naturais e as ciências humanas, e de Kuhn uma crítica correta da caracterização de Taylor das ciências naturais. Minha argumentação apontará para uma reconceptualização da unidade das ciências.

\section{$O$ argumento de Taylor para a falta de unidade entre as ciências naturais e as ciências humanas}

Taylor sustenta que diferentes tipos de entendimento estão - ou devem estar - presentes nas ciências naturais e humanas. ${ }^{3}$ Os diferentes tipos são necessários para fornecer descrições explicativas de seus respectivos objetos de investigação, as quais por sua vez requerem diferentes tipos de termos descritivos, um mobilizando termos absolutos, o outro termos relacionados com o sujeito. Termos relacionados com o su- 
jeito designam propriedades relacionadas com o sujeito, propriedades que uma coisa possui em virtude (1) de ser um objeto da experiência de sujeitos humanos; (2) de sua situação no contexto da ação, interesse ou preocupação humanas; e (3) de como ela afeta os seres humanos. Termos absolutos designam propriedades que não são relacionadas com o sujeito, propriedades que as coisas têm sem levar em conta suas relações com os seres humanos.

Taylor sustenta ainda que o objeto de investigação da ciência natural é "o mundo natural", que existe independentemente dos observadores humanos $-{ }^{4} \mathrm{ou}$, mais modestamente, partes do mundo material e como elas se afetam mutuamente, "mesmo quando não estamos em cena ou não estamos desempenhando um papel" (Taylor, 1980, p.47). Dado este objeto de investigação, seu entendimento precisa ser articulado com termos absolutos; caso contrário, o entendimento não seria fiel a seu objeto. Na prática, esses termos são caracteristicamente matemáticos, de tal modo que o entendimento nas ciências naturais toma tipicamente a forma de representação das leis e estruturas subjacentes aos fenômenos investigados, isto é, ele é articulado em teorias.

O entendimento de seres humanos em qualquer profundidade e significância deve ser diferente para Taylor, pois seres humanos constituem um tipo diferente de objeto. Em particular, o entendimento dos seres humanos requer a atribuição de "características de desejabilidade" ou, mais precisamente, a referência à estrutura de valores hierarquicamente ordenada que se expressa na vida de uma pessoa. Tais estruturas de valores definem os mundos dos agentes: o que é significante para eles, o que é

3 Minha exposição das posições de Taylor provém em grande medida de seu ensaio "Understanding in the human science" (Taylor, 1980), complementado por Taylor (1981) e de vários ensaios em Taylor (1985b). Para as posições de Kuhn baseei-me principalmente em Kuhn (1970) com clarificações extraídas de Kuhn (inédito). Partes importantes da minha discussão, especialmente minha terminologia, foram influenciadas por Bhaskar (1975).

4 Proponho que qualquer distinção entre objetos e propriedades que são dependentes de relações com agentes humanos e aquelas que não o são devam ser consistentes com as seguintes condições: (1) Nossa apreensão de objetos é mediada pelos nossos poderes conceituais. (2) Somos parte do mundo, agentes causais nele; não podemos apreender o mundo a não ser em virtude da nossa atuação nele. (3) Somos capazes de apreender segmentos do mundo em que a atuação humana não é um fator causal relevante - por meio de práticas que os relacionam a segmentos (experimentos) onde a atuação é relevante. (4) Somos capazes de extrapolar esta apreensão para espaços ainda mais afastados de nossa experiência e atuação, até para épocas anteriores à existência dos seres humanos. (5) A extrapolação pode ser estendida ao aparecimento dos seres humanos (com suas capacidades distintivas). (6) Em princípio, mais aspectos da vida humana são explicáveis da mesma maneira. Deixo em aberto se as distinções de Taylor são consistentes com essas condições. 
desejável e indesejável para eles, o que acham admirável e desprezível, que emoções exprimem, seus interesses e aspirações, o que consideram uma vida plena. Entender os outros requer acesso a suas estruturas de valor, entender seu ponto de vista mesmo sem compartilhá-lo - muito parecido com a apreensão, central para o argumento de Kuhn, dos léxicos estruturados da ciência passada. Conseguir tal acesso é uma tarefa interpretativa, necessariamente interna às ciências humanas e envolve além disso termos inextricavelmente relacionados com o sujeito.

Assim, para Taylor, as ciências humanas diferem das ciências naturais em dois aspectos. Primeiro, devem usar termos relacionados com o sujeito. Segundo, a interpretação é interna a elas; não é, por assim dizer, inteiramente lançada no pano de fundo implícito da matriz disciplinar. Uma terceira diferença se segue: as ciências humanas, diferentemente das ciências naturais, não podem ser isentas de valores. Por um lado, uma vez que, por definição, os termos absolutos não são portadores de valores, as teorias científicas não podem ter implicações avaliativas, enquanto o entendimento nas ciências humanas pode tê-las. Por outro lado, uma vez que os termos absolutos são dissociados de interesses pode haver práticas nas ciências naturais que conduzam ao acordo intersubjetivo entre os pesquisadores (não importando as suas diferentes estruturas de valores). Em contraste, a apreensão das estruturas de valores de outras pessoas pode requerer pesquisadores que exprimam eles mesmos estruturas de valor particulares; uma pessoa pode não ser capaz de compreender os outros, a não ser que seja (moralmente) um certo tipo de pessoa. Comparemos isto com o relato de Kuhn acerca de como os cientistas apanhados pela estrutura do léxico implícito na conduta da ciência normal não estão bem afinados para empreender as tarefas interpretativas da história da ciência. Aquilo que Kuhn postula como acontecendo entre diferentes épocas nas ciências naturais pode acontecer entre diferentes práticas morais das ciências humanas. Algumas estruturas de valores, assim como um léxico estruturado, podem diminuir os poderes de interpretação, de reconstrução imaginativa e de comunicação entre diferenças. Nas ciências naturais, pelo menos, há ganhos compensadores.

A peça central do argumento de Taylor de que as ciências naturais e as ciências humanas proporcionam diferentes modos de entendimento é sua caracterização dos diferentes objetos de investigação, e a distinção ontologicamente fundamentada entre termos absolutos e termos relacionados com o sujeito. Taylor reconhece entretanto que o argumento abstrato precisa ser complementado com críticas concretas das várias teorias que têm sido propostas nas ciências humanas, mostrando que na verdade elas falham em produzir esclarecimento comparável ao obtido por méto- 
dos interpretativos, a respeito dos fenômenos distintiva e caracteristicamente humanos. Numa série de publicações (por ex. Taylor, 1964; 1985a, cap.5-8), ele oferece tais críticas concretas de teorias behavioristas, cognitivistas e funcionalistas. Não vou avaliar essas críticas, se elas refletem apenas o status "pré-paradigmático" desses campos, ou se podem ser extrapoladas para teorias em outros campos a que ele não se dedicou.

\section{O contra-argumento kuhniano}

As teses de Taylor sobre as ciências humanas são, acredito, fundamentalmente corretas. Entretanto, vou argumentar que sua descrição da diferença entre os objetos de investigação é defeituosa; que sua distinção entre termos absolutos e relacionados com o sujeito é insustentável, embora haja uma distinção importante aproximadamente coextensiva; e que ele deixa escapar a real unidade entre as ciências naturais e as ciências humanas.

O argumento básico contra a descrição de Taylor do objeto da ciência natural foi evidentemente apresentado por Kuhn. Não há nada nas práticas científicas que nos autorize a afirmar que a teoria proporciona entendimento do mundo natural, ou de objetos no mundo natural, independentemente das relações destes com os seres humanos. Isto não significa que não se possa adquirir conhecimento de objetos no mundo natural; somos parte do mundo natural. Apreendemos o mundo contra o pano de fundo de uma matriz disciplinar essencialmente histórica, enquadrada por um léxico estruturado essencialmente histórico. Este é nosso mundo, o mundo de que temos conhecimento, um mundo construído no decorrer de práticas humanas. Isto posto, a distinção articulada por Taylor entre termos relacionados com o sujeito e termos absolutos simplesmente se dissolve; todos os termos são relacionados com o sujeito. Concordo. Vou apenas acrescentar um pequeno adendo ao argumento de Kuhn.

Os termos que Taylor pretende fazer cair na categoria de absoluto são quase todos quantitativos. A aplicação de termos quantitativos a objetos particulares sempre requer alguma operação de medida (em geral uma série de cálculos matemáticos). A medição requer instrumentos, e que o objeto a ser medido seja colocado numa relação apropriada com o instrumento. A medição refere-se a uma relação entre o objeto e o instrumento, um artefato humano que inserimos na natureza. Sugiro que o significado de qualquer termo quantitativo não pode ser dissociado da (nem pode ser reduzido à) operação de instrumentos. Ora, procedimentos de medição são compartilhados por uma grande variedade de práticas hu- 
manas, expressivas de muitos interesses diferentes - dando a impressão de que o significado dos termos quantitativos é dissociado de nossos contextos práticos, deixando escapar o fato de que tais termos não têm sentido fora do contexto de práticas científicas com as características apontadas por Kuhn. Em vez de lidar com objetos dissociados das práticas humanas, a ciência almeja entendê-los como resultado de interações experimentais e de medida.

Concordo portanto com Kuhn que não há uma distinção relevante ontologicamente fundamentada entre termos absolutos e relacionados com o sujeito. A atribuição de propriedades a objetos não se separa do pano de fundo das matrizes disciplinares, e se faz de acordo com procedimentos, envolvendo freqüentemente intervenção ativa, para aplicar termos a objetos. No interior de nossos modos de entendimento, as coisas não têm propriedades, a não ser na medida em que lhes aplicamos predicados. Qualquer propriedade relaciona-se com práticas humanas, tanto assim que com mudanças nas práticas ao longo da história da ciência mesmo os termos mais absolutos, tais como o predicado unário massa, foram descartados nas nossas teorias mais fundamentais. Mesmo assim, uma outra distinção entre termos, aproximadamente coextensiva com a de Taylor, pode ser estabelecida.

Vejamos o contexto que motiva a nova distinção. Em primeiro lugar, a ciência representa adequadamente algumas das tendências e possibilidades dos objetos naturais; estas não foram criadas por seres humanos, embora o fato de ficarem em evidência ou de se realizarem possa ser produto da atividade humana (freqüentemente experimental). Além disso, nas teorias, a ciência relaciona essas tendências e possibilidades a (postulações de) estruturas e leis subjacentes, com tanto sucesso que, freqüentemente, a partir delas, assim postuladas, podemos gerar (e confirmar empiricamente) tendências e possibilidades em espaços consideravelmente afastados dos espaços iniciais de investigação. Segundo, precisamos separar em nossas explicações os espaços nos quais existem influências causais humanas daqueles em que estas estão ausentes; embora os seres humanos sejam parte da ordem causal, sua influência causal obviamente não é onipresente. Nas ciências naturais modernas, tentamos alcançar um entendimento dos objetos o qual abstrai de qualquer influência causal humana sobre eles (assim como na cinemática lidamos com o movimento abstraindo das forças em operação). Teorias bem estabelecidas articulando representações das estruturas e leis subjacentes confirmam o sucesso dessa tentativa, nossa habilidade de lidar com fenômenos em certos espaços representados como causalmente gerados a partir das estruturas e leis subjacentes. Tais espaços são na maioria experimentais e 
tecnológicos, espaços delimitados cujas condições de contorno foram criadas por seres humanos precisamente para impedir influências causais humanas sobre os acontecimentos no interior desses espaços.

Chamarei fisicalistas os termos (não-lógicos) usados nas representações das estruturas e leis subjacentes. Eles são usualmente quantitativos e aplicados a objetos em conseqüência de operações (medição, cálculo, e observações apoiadas em instrumentos, experimento) cujos resultados são compartilhados intersubjetivamente no interior da comunidade disciplinar - portanto onde toda interpretação é empurrada para a matriz disciplinar implícita, na qual todos os membros da comunidade fizeram seu aprendizado, interpretação que vem potencialmente para o proscênio apenas quando as práticas da comunidade são fundamentalmente desafiadas. Entre os termos não fisicalistas, consideremos aqueles que chamo visivelmente interpretativos, aqueles cuja aplicação depende explicitamente de práticas interpretativas nas quais não se pode contar com a concordância intersubjetiva. Todos os termos intencionais se encaixam nessa categoria. Reformulada desta maneira, a distinção é pouco nítida, gradativa e, sem dúvida, historicamente variável, mas mesmo assim importante e suficiente para satisfazer a motivação do parágrafo anterior.

Termos fisicalistas podem ser usados para fornecer um entendimento adequado de fenômenos em certos espaços. Já indiquei que esses são principalmente os espaços delimitados do experimento e da tecnologia. As condições de contorno de tais espaços são passíveis de descrições fisicalistas que, para fins explicativos no interior do espaço, são tudo o que é necessário, uma vez que funcionam como variáveis independentes. Contudo, elas (assim como certos efeitos produzidos nos espaços) são passíveis também de descrições não fisicalistas, incluindo algumas que usam termos visivelmente interpretativos, por exemplo, que as condições desempenham um papel determinado num esquema de pesquisa de um experimentador com certos objetivos. Em geral as condições de contorno desses espaços não podem (pelo menos no presente e com as estratégias reducionistas comumente conhecidas) ser explicadas com o uso de termos fisicalistas, uma vez que sua existência é explicável em termos de seu lugar nos projetos humanos, de tal modo que as estruturas e leis subjacentes descobertas são, em primeiro lugar e na maioria dos casos, espaços feitos pelo homem. Mas elas também podem, sob certas condições, ser extrapoladas para espaços e fenômenos de origem não-humana, nos quais não há influências causais humanas e cujas condições de contorno são passíveis de explicação fisicalista, inclusive para espaços de interesse cosmológico como o sistema planetário (Lacey, 1984). 
Portanto, embora possa haver resultados positivos decorrentes de procurar entender os objetos naturais abstraindo de influências causais humanas, procurar tal entendimento a respeito dos seres humanos, em contrapartida, seria trivial e mesmo sem sentido. Não se segue entretanto que um entendimento significativo de fenômenos humanos não possa ser expresso em teorias que usam apenas termos fisicalistas; alguns fenômenos da vida humana claramente requerem explicações fisicalistas. $A$ priori permanece em aberto se algumas ou todas as influências humanas podem ser compreendidas em termos do mesmo tipo de princípios teóricos, usando termos fisicalistas que fornecem entendimento de espaços fechados, livres de influência humana; isto é, se, em princípio e mais cedo ou mais tarde, as influências humanas podem ser reduzidas a outras. Kuhn, com seu agnosticismo sobre a questão, deixa as coisas neste pé. Mas pode valer a pena especular sobre as condições que precisam existir para o desenvolvimento de uma comunidade em ciências humanas que almeja gerar ciência normal kuhniana. ${ }^{5}$ É o que farei daqui a pouco.

\section{O controle tecnológico e a racionalidade da ciência}

Por que Taylor resiste à crítica, derivada de Kuhn, apresentada na seção anterior? Há uma razão, desenvolvida no seu ensaio Rationality (Taylor, 1985b). É a de que a ciência natural informa, explica e dá origem à tecnologia. Embora não negue que a ciência natural seja praticada dentro de uma matriz disciplinar implícita, Taylor alega que o fato da tecnologia mostra que seus produtos teóricos transcendem tanto o passado como o contexto que os produziu, exigindo adesão cognitiva por meio de todos os esquemas culturais e interpretativos. Argumenta que a teoria é capaz de explicar o controle tecnológico porque oferece uma apreensão mais ampla, mais abrangente das entidades do mundo natural; a tecnologia é a organização das forças e poderes que explicam os fenômenos naturais em que não há influências humanas, e a teoria fornece uma compreensão de tais forças e poderes.

5 Caso se aceite o ponto de vista de Taylor a respeito da ciência natural e os itens de (4) a (6) da nota 4, pode parecer que haja razões metafísicas para adotar este rumo. Taylor não se deixa impressionar por estas razões, uma vez que valoriza o poder explicativo demonstravelmente obtido com termos visivelmente interpretativos, mais do que promessas de economia explicativa. 
Pois bem, é de fato verdade que a teoria científica forneça compreensão dos espaços tecnológicos e o entendimento adequado de seus modos de operação material e das possibilidades e poderes dos controles tecnológicos. A teoria consegue fazer isso por causa de suas raízes em práticas experimentais e de seu bem demonstrado poder explicativo e preditivo em espaços fechados. Nada mais é necessário. É tanto gratuito quanto, de acordo com Kuhn, em última análise ininteligível, recorrer às coisas como elas são independentemente da interação humana. A explicação do controle tecnológico não precisa de tal recurso. E as alegações de validade transcultural da teoria são fundadas na continuidade da tecnologia com o tipo de interação com as coisas materiais necessário para a vida humana, e acima de tudo na crescente hegemonia do modo tecnológico de interação e na ubiqüidade de suas implicações no mundo inteiro. A teoria é significante para entender o moderno mundo da experiência vivida porque pode explicar o funcionamento material dos controles tecnológicos. As alegações da teoria residem não no fato de ter um objeto neutro mas em ser portadora de uma forma de entendimento necessária para a apreensão do modo característico de interação com a natureza no mundo moderno (Lacey, 1986).

É a importância do controle, não a isenção de valores, que está por trás da pretensão característica que a teoria nos apresenta. A teoria é o tipo de entendimento que informa o controle. Mais precisamente, ela informa o controle mais sistemática e extensamente que o mero conhecimento das regularidades empíricas de um domínio. Isto não significa que toda teoria científica seja capaz de informar controles tecnológicos, ou que adotar objetivos aplicados imediatos, ou que a geração de aplicações práticas funcione como um meio essencial de confirmar teorias. Em vez disso, a teoria representa objetos como devem ser representados para fins de controle (deixando aberta a possibilidade de que alguns dos objetos dos quais ela fornece entendimento não sejam - e, por causa de limitações humanas, não possam ser - eles próprios susceptíveis a influências controladoras humanas). Afirmei na seção anterior que a teoria representa objetos de tal maneira que eles sejam explicáveis em termos das estruturas e leis subjacentes. Ambas as descrições são corretas. O entendimento necessário para o controle é o que representa o domínio de possibilidades que pode ser gerado a partir das estruturas e leis subjacentes.

Usando apenas termos fisicalistas e portanto desprovidos de relações de implicação com enunciados de valores, a teoria oferece representações das condições sob as quais as várias possibilidades (também caracterizadas fisicalisticamente) podem ser realizadas. As condições e possibilidades, caracterizadas desta maneira, são abertas a uma variedade de outras possíveis descrições, dependendo do lugar que possam vir a 
ocupar em práticas sociais mais amplas, das quais - de acordo com um ponto de vista amplamente aceito - derivaria qualquer valor que pudessem ter. Ainda segundo tal ponto de vista, a teoria em si mesma é neutra neste aspecto; ela se pronuncia sobre o possível, não sobre o desejável. Tal concepção deixa de levar em conta duas constatações. Primeiro, uma vez que a teoria informa o controle, ela pode não ter um papel significativo onde não é apropriado lidar com as coisas como sujeitas a controle. Segundo, a teoria se desenvolve em interação dialética com o progresso tecnológico; suas condições materiais e sociais apenas se encontram numa sociedade em que o controle da natureza é um valor primário, e se pode contar mais com elas quando as práticas de controle são hegemônicas. Em outras sociedades, o significado da teoria fica diminuído, ou melhor, delimitado. O papel das práticas de controle no mundo moderno da experiência vivida assegura que a significância da teoria não vai se extinguir.

O controle ocupa um lugar elevado na estrutura de valores que é parte das matrizes disciplinares das práticas científicas modernas. Ele é implícito e raramente percebido, e isto explica, nas ciências humanas, tanto a atração pela teoria quanto seu perigo. A presença real da teoria nas ciências humanas pode representar não a redução bem-sucedida, mas o sucesso em suprimir o que é caracteristicamente humano (por exemplo, as práticas comunicativas ou a ação informada por deliberação pessoal) em certos espaços por meio da introdução bem-sucedida de controles sobre o comportamento humano - ou seja, pela criação de espaços em que os agentes humanos comunicativos se tornam, por causa dos limites, opções e controles dos espaços, objetos sujeitos a controle (Lacey \& Schwartz, 1986). A teoria pode mapear adequadamente as regularidades empíricas de tais espaços embora não apreendendo o domínio completo das possibilidades humanas presentes. $\mathrm{O}$ entendimento interpretativo é indispensável onde as práticas comunicativas entre as pessoas são fortes; ele cede o lugar à teoria quando os controles solapam aquilo que é característico dos seres humanos. ${ }^{6}$ Segue-se que procurar apenas entendimen-

6 O entendimento tanto se ajusta às práticas quanto as molda, numa dialética sempre em movimento. Se a teoria viesse a articular com alguma profundidade a esfera do distintivamente humano, então isto causaria revisões nas avaliações morais a respeito do controle de seres humanos. Da mesma forma, é bem possível que a promoção de práticas comunicativas (perpassando por um domínio tão amplo quanto possível de pontos de vista) venha a contrabalançar a atração do materialismo reducionista. À medida que viermos a descartar teorias que (explícita ou implicitamente) representam os seres humanos como sujeitos a controle, talvez os objetos de investigação nas ciências naturais deixem de ser concebidos abstraindo-se de suas dimensões ecológicas e sociais. 
to que mobilizem termos fisicalistas, em vez de refletir a isenção de valores, reflete a hegemonia do controle - ou, se se preferir, a neutralidade ao longo desta moderna multiplicidade de estruturas de valores na qual o controle ocupa um lugar proeminente.

\section{Os valores epistêmicos e o papel do controle}

Tanto para Taylor quanto para mim, então, a conexão com o controle tecnológico é um componente essencial do tipo de entendimento fornecido pela moderna teoria científica e de suas pretensões à racionalidade. Para Kuhn não é assim. Não desejo sugerir que Kuhn negue a importância das conexões, e mesmo afinidades existentes entre a ciência e a tecnologia, por exemplo, que a tecnologia estimule o avanço científico, que forneça muitas de suas condições materiais e justifique politicamente sua disponibilidade, e que a ciência aplicada seja uma parte importante da tecnologia. Estes são fatos importantes da sociologia e da história social da ciência. Porém, Kuhn nega que as conexões com a tecnologia sejam parte da explicação do entendimento e da racionalidade científicos e de sua significância, embora algumas vezes eles possam fornecer uma parte substancial da evidência favorável à teoria. Ele sustenta que o entendimento científico e a escolha de teorias são marcados por uma racionalidade que explica a significância da ciência e que é adequadamente descrita sem apelo à tecnologia. Com o objetivo de clarificar sua posição, vou me concentrar em seu ensaio "Objetivity, value judgement, and theory choice" (Kuhn, 1977), cujas virtudes têm sido subestimadas.

Nas narrativas históricas kuhnianas estão presentes as descontinuidades freqüentemente enfatizadas e as mudanças de matrizes disciplinares e léxicos ordenados que fornecem as ferramentas conceituais para a construção de teorias. Há também uma constância menos visível dentro das comunidades formadas pelos cientistas, um compromisso (incorporado na comunidade, embora não necessariamente de maneira inequívoca em qualquer membro individual) com um conjunto de valores: valores epistêmicos, incluindo a precisão, a simplicidade, a consistência, a abrangência explicativa, o poder de previsão e a fecundidade em resolver quebra-cabeças e gerar outros novos. ${ }^{7}$

Os valores epistêmicos, de acordo com Kuhn, podem ser demarcados de valores sociais e morais, inclusive o da primazia do controle. A escolha de teorias é propriamente feita de acordo com o objetivo de incorporar tão completamente quanto possível uma estrutura ordenada desses valores. Isto permanece verdadeiro através de períodos de descontinuidade, sem dúvida facilitando a tarefa de reconstruir as matrizes dis- 
ciplinares do passado. Parte da vantagem de se explicar a racionalidade científica em termos epistêmicos em vez de regras indutivas reside no fato de que esta racionalidade ganha certa flexibilidade e abertura a interpretações controvertidas. A ordenação, ponderação e interpretação de valores específicos pode variar com o pesquisador, o momento, ou o contexto. Uma teoria é escolhida quando há consenso na comunidade, sustentado ao longo de extensa discussão crítica, de que, dentre as estruturas ordenadas de valores epistêmicos, a preferida é adequadamente expressa na teoria. Parte do que acontece no encerramento de um período de descontinuidade é a reobtenção de um consenso (que havia sido quebrado no início do período) a respeito da estrutura ordenada de valores preferida. Temos assim uma descrição da racionalidade da aceitação de teorias - e, associada a esta, uma descrição a respeito do que impulsiona o processo da ciência - a qual abstrai de suas conexões com preocupações práticas, e portanto com outras preocupações ligadas à cultura. Acrescentar um valor moral, como a primazia do controle ou das aplicações tecnológicas vai contra o espírito desta descrição.

Kuhn também sugeriu (em discussão, como resposta a meu argumento) que adicionar o controle à lista dos valores epistêmicos, especialmente no caso de ser colocado numa posição elevada na hierarquia de valores, distorceria e até mesmo subverteria o processo da ciência. Ele passou dessa sugestão a uma crítica a muitos aspectos da prática corrente da ciência, que vê como se submetendo à pressão social (talvez visando a conseguir acesso aos recursos necessários à pesquisa) para colocar objetivos aplicados e práticos ao longo de, e talvez à frente dos, valores epistêmicos. Concordo com a crítica de Kuhn, ainda mais quando esses objetivos são parte de pesquisa secreta privatizada ou promovida pelo governo. Entretanto, meu argumento, apresentado na seção anterior e

\footnotetext{
7 Permanece aberta a questão referente ao que exatamente deveria ser incluído em uma lista de valores epistêmicos. Por exemplo, Putnam (1988) inclui a retenção, tanto quanto possível, de teorias antecedentes, MacIntyre (1977) a capacidade de construir uma narrativa que explique o que é correto e o que é incorreto em teorias antecedentes, e Shapere (em conversa) a consistência demonstrada com a melhor teoria física fundamental disponível. E eu generalizaria "poder de previsão" para "capacidade de mapear as possibilidades dos domínios de investigação". Qualquer que seja a lista, ela precisa ser fundamentada numa discussão a respeito dos fins da ciência. Fundamentar a lista desta maneira não implica que os valores epistêmicos, assim demarcados, possam ser interpretados na prática dissociados de sua interação com outros valores - não mais que a interpretação de um valor como a liberdade pode ser dissociada da interação com um valor como a igualdade. A demarcação não implica o isolamento interpretativo. Para mais detalhes a respeito dos valores epistêmicos, ver Lacey (1997b).
} 
clarificado a seguir, não se origina do fato empírico (e claramente contingente) de que uma boa parte da prática científica contemporânea coloca objetivos práticos concretos na mesma lista que os valores epistêmicos. Observe-se que Bacon concordaria com Kuhn neste ponto, contudo ele via a meta da ciência como sendo a de expandir a capacidade dos seres humanos de exercer controle sobre as coisas.

O que exatamente está faltando na narrativa histórica de Kuhn que seria remediada pela introdução de conexões com o controle tecnológico na história? Eis aqui alguns dos elementos:

a) Uma explicação de por que certos valores epistêmicos são interpretados de certas maneiras.

Por exemplo, na ciência física moderna (em contraste com a ciência grega) a abrangência explicativa é interpretada de uma maneira que denomino "extensiva" (wide-ranging) em vez de "completa" (full) (Lacey, 1986). As teorias são valorizadas mais por gerar explicações cobrindo uma extensa área e variedade de domínios, cada um dos quais definido pela presença de certas condições de contorno, em vez de serem valorizadas por dar conta de todos os aspectos dos objetos nestes domínios, incluindo o porquê da existência das condições de contorno, particularmente suas bases sociais e os efeitos ecológicos e sociais do comportamento dos objetos. Analogamente, na ciência moderna a precisão tende a ser interpretada em termos de exatidão quantitativa, em vez de ser interpretada em termos de noções mais amplas de adequação empírica que envolve descrições qualitativas.

b) Uma explicação da hierarquia (ranking) dos valores epistêmicos dentro da matriz disciplinar da ciência moderna.

Por que, por exemplo, a precisão (exatidão quantitativa) é tão proeminente? E por que a consistência com as melhores teorias físicas do momento é mais proeminente que a abrangência explicativa? (Muitas vezes explicações intencionais, apesar de seu poder de explicação, são rejeitadas como inadequadas por ser duvidosa sua coerência com a teoria física fundamental.)

c) Uma explicação da centralidade do experimento na ciência moderna.

Qualquer pretensão legítima a um entendimento da natureza (ou do mundo da experiência vivida) deve se assentar em investigações empíricas que incluem mais que as experimentais. Em experimentos bem-sucedidos descobrimos as tendências da natureza e as regularidades dos espaços delimitados. Para estabelecer que tais tendências também são in- 
fluências significativas em espaços não experimentais é necessária a investigação empírica direta desses espaços. A confiança de que pode haver uma passagem rápida do experimento para a natureza (bem como para espaços tecnológicos) é uma característica da ciência moderna, e freqüentemente a passagem é feita sem a consciência de que ela requer fundamentação (Lacey, 1984).

d) Uma explicação de por que a atividade de resolver quebra-cabeças da ciência moderna veio a ser reconhecida com o significativa para tantas culturas.

Não basta que haja quebra-cabeças a serem resolvidos, como os há no jogo de xadrez, pois resolver e gerar tais quebra-cabeças requer da sociedade o fornecimento de consideráveis recursos materiais e sociais, freqüentemente às custas de outras opções (inclusive cognitivas). Há inúmeros quebra-cabeças para a investigação dos quais a sociedade fornece poucos recursos, por exemplo, as raízes sociais da pobreza, da marginalidade e da cultura das drogas, e outros para os quais ela fornece recursos apenas em situações de emergência, por exemplo, o impacto ecológico da modernização. Por que veio a ser tão amplamente aceito que quebra-cabeças formulados em termos fisicalistas são merecedores de investigação permanente?

Kuhn parece não considerar que a ausência de explicações para esses quatro fenômenos seja uma falha séria. Do quarto pode-se facilmente dar conta pelo tipo de análise sociológica que, como ele reconhece, complementa adequadamente suas próprias narrativas históricas; trata-se de um fenômeno social que pode tanto promover quanto (como já foi mencionado) ameaçar a pesquisa moldada por valores epistêmicos. Os outros três, para ele, não requerem análises profundas, sendo simplesmente derivadas dos processos de tentativa e erro no interior da comunidade comprometida com os valores epistêmicos; descobriu-se que os quebra-cabeças que eles haviam herdado do passado poderiam ser resolvidos por meio de teorias mobilizando apenas termos fisicalistas, e que tais soluções para antigos quebra-cabeças abriu um vasto território de novos quebra-cabeças que ainda não foi completamente explorado. Para Kuhn, os termos fisicalistas não refletem privilégio metafísico algum. Eles constituem o léxico ordenado da moderna matriz disciplinar que estrutura um empreendimento altamente bem-sucedido de resolução de quebra-cabeças (cujas soluções, por sua vez, são extremamente valorizadas pela sociedade). As coisas poderiam ter resultado em algo diferente, 
e podem novamente tornar-se algo diferente no futuro, ou num outro contexto social.

Não obstante, uma história mais profunda pode ser contada, com base na análise da seção anterior, e resumida assim. (1) A teoria (mobilizando termos fisicalistas usados para representar as leis e estruturas subjacentes das coisas) fornece entendimento de objetos e espaços dos quais os tecnológicos (e experimentais) são exemplares. (2) O moderno mundo da experiência vivida passou a ser dominado por objetos tecnológicos, de tal maneira que lidar com ele exige que se recorra ao entendimento teórico. (3) A teoria fornece o tipo de entendimento necessário para exercer controle sobre as coisas; ela apreende as coisas tais como devem ser apreendidas para fins de controle (quer as coisas assim compreendidas possam ser objeto de controle, quer isto não seja possível), expandindo com isso a capacidade humana de controlar as coisas. (4) A primazia do controle sobre a natureza é um valor característico da modernidade. Há portanto uma razão para que se procure entender as coisas consideradas como objetos susceptíveis de controle (além da resolução de antigos quebra-cabeças e a geração de novos), a saber, o desejo de aumentar a capacidade humana de controle - e viver eficazmente no mundo moderno envolve compartilhar de alguma maneira este desejo. Isto é verdade, quer se aceite a primazia do controle, quer simplesmente se reconheça a centralidade dos objetos tecnológicos no moderno mundo da experiência vivida.

Minha sugestão é a de que o léxico estruturado da ciência moderna foi restringido de modo que as coisas sejam representadas nele da maneira exigida pelos objetivos de controle (Lacey, 1998), ${ }^{8}$ e de que isto molda

8 Cf. a nota 4. Pode haver outras razões para o envolvimento em práticas que representam as coisas como objetos explicáveis em termos de estruturas e leis subjacentes. Uma delas seria a de que este é o meio de conseguir entendimento de certos fenômenos, espaços e épocas cosmologicamente significantes. Conseguir entendimento cosmológico pode na verdade constituir a meta da ciência para alguns cientistas. Não obstante, suas práticas envolvem inevitavelmente a representação das coisas como objetos susceptíveis de controle, extrapolando a partir dos espaços em que podemos efetivamente exercer controle e usar instrumentos sofisticados que são produtos da tecnologia avançada. Esta não é uma alternativa à meta baconiana num sentido amplo, mas sim um passo além dela que pode manter certo grau de independência relativa. Outra razão pode motivar programas de pesquisa, por exemplo, aqueles tendo como objetivo o entendimento de competências cognitivas que são concebidos por seus proponentes como estando em oposição ao controle dos seres humanos. Embora não negando a seriedade de tal motivação, eu levantaria a questão de se uma explicação fisicalista da competência pode manter tal oposição. É possível que esforços "científicos" para apreender competências cognitivas sejam enraizados em abordagens biológicas que não são ligadas ao controle, e assim não limitam o entendimento científico à teoria (tal como a defini). Não é possível dar prosseguimento a tal discussão nesta nota. 
a interpretação dos valores epistêmicos. Os dois primeiros fenômenos são assim imediatamente explicáveis. O controle requer acesso às estruturas e leis subjacentes das coisas, e para ter acesso aos limites de suas possibilidades deve-se abstrair do contexto social e ecológico dos controles (reais ou desejados), e tais limites serão maiores à medida que se consiga estabelecer teorias de grande alcance. Daí a atração pelo entendimento extensivo, em vez de completo. Analogamente, a precisão (exatidão quantitativa) é altamente valorizada. E a experimentação é central porque envolve casos exemplares de obtenção de controle, e a única via de acesso confiável às estruturas e leis subjacentes.

Segue-se que o significado da teoria - sua importância e papel na vida humana, inclusive a atividade cognitiva - depende de quão saliente é o controle na estrutura de valores de uma pessoa (ou de uma cultura). A teoria deixa inexplorados, na maior parte, tanto as condições (inclusive as condições sociais) que criam e mantêm os espaços a respeito dos quais ela fornece entendimento, quanto os efeitos dos acontecimentos de tais espaços nos ambientes naturais, humanos e sociais. O entendimento teórico não dá conta completamente dos objetos com que lida, embora nos melhores casos sua aplicabilidade percorra amplamente numerosos espaços. Para quem o controle não é proeminente, a significância do entendimento teórico pode ser qualificada pelo juízo de que os requisitos "hi-tech" [aspas no original] de grande parte da pesquisa contemporânea estão disponíveis apenas numa sociedade cujo comprometimento com o avanço tecnológico (tanto na pesquisa e desenvolvimento quanto na contínua implementação como parte do sistema econômico) é ao mesmo tempo uma fonte de injustiça ou agressão. ${ }^{9}$ Eles podem procurar mudar a forma do mundo da experiência vivida de tal maneira que o controle deixa de ser hegemônico, mas em vez disso fica altamente restrito pelas exigências de outros valores, por exemplo, certa concepção de justiça social, democracia e responsabilidade em relação ao futuro. Os objetos naturais

9 Algumas vezes se argumenta que tais pessoas estejam tentando impor restrições sociais ou valorativas sobre a pesquisa pura - ou seja, pesquisa impulsionada e avaliada apenas por valores epistêmicos. Ou pode parecer um conflito entre a expressão de valores epistêmicos, ou de certos valores sociais. Na verdade, na minha concepção não existe pesquisa pura no sentido definido. Os valores epistêmicos desempenham um papel crucial na pesquisa, porém sua interpretação é sempre estruturada por alguns valores sociais, e o apoio à sua expressão é ligado à expressão de certos valores sociais. O tipo de conflito em discussão é no fundo um conflito de valores sociais. Isto não é fácil de ser percebido numa sociedade que tende a tomar a primazia do controle da natureza como um valor universal. 
seriam estudados explicitamente em termos de sua relação com a ordem social, e não simplesmente como objetos cujas possibilidades são geradas pelas estruturas e leis subjacentes em que seu papel na ordem social é apenas implícito (Lacey, 1997a). ${ }^{10}$

\section{Conclusão}

Como conclusão sugiro que a não ser que tal mundo da experiência vivida alterado em sua forma seja criado, a concepção de Taylor a respeito das ciências humanas, embora constituindo uma alternativa freqüentemente discutida, permanecerá marginal em relação às práticas explícitas (e com certeza às articulações das metas) de muitas das ciências humanas. Isto se deve ao fato de que as condições sociais necessárias para a expressão hegemônica da primazia do controle sobre a natureza requer o ajuste de relações institucionais e sociais às contingências do progresso tecnológico, assim como o exercício do controle sobre os seres humanos. Assim, exatamente as mesmas condições que alimentam a aquisição de entendimento predominantemente teórico dos objetos materiais pressionam a favor da promoção do entendimento teórico dos seres humanos. (Esta pode ser a razão social para o apelo do materialismo reducionista.)

Existem assim relações recíprocas entre as ciências naturais e as ciências humanas; elas se informam mutuamente pela mediação das condições sociais que mantêm tanto sua prática quanto os espaços dos quais elas caracteristicamente fornecem entendimento. Onde o controle ocupa um lugar elevado nas estruturas de valores dominantes de uma sociedade (ou de uma época), a pressão para estender o modelo da ciência natural moderna para as ciências humanas é grande. Onde o controle não ocupa tal posição nas estruturas de valores dominantes, a pesquisa nas ciências humanas contribuirá para determinar a significância da teoria e para dirigir seu foco. Neste caso, a teoria fornecerá entendimento de certos espaços fechados, a saber, aqueles que desempenham um papel ligado à promoção do projeto social. É verdade que o entendimento teórico deriva

10 O sucesso de tais estudos, e a abertura de novos programas de pesquisa próprios, seriam subseqüentemente necessários se a atração pela teoria tiver de ser questionada (e não apenas entendida - f. nota 6). Mesmo assim, se tais resultados não forem obtidos, permanece a questão de se isto se deveria a uma incapacidade inerente ou simplesmente porque a pressão imperialista da modernidade o impediu. 
(dialeticamente) de práticas de controle, e se qualquer forma de entendimento for dialeticamente ligada com alguns tipos de prática, então a redutibilidade e falta de unidade deixam de ser as únicas opções. Uma unidade profunda baseada na reciprocidade das ciências humanas e naturais parece ser possível.

LACEY, H. Interpretation and theory in natural and human sciences: comments on Kuhn and Taylor. Trans/Form/Ação (São Paulo), v.20, p.77-93, 1997.

- ABSTRACT: The aim of the paper is to extract from Taylor's writings a critique of Kuhn's suggestion of the possible unity of the natural and the human sciences, and from Kuhn a critique of Taylor's account of the natural sciences. An outcome of this enterprise will be a re-construal of the unity of the sciences.

- KEYWORDS: Unity of science; understanding; physicalism; technological control; epistemic values.

\section{Referências bibliográficas}

BHASKAR, R. A Realist Theory of Science. Atlantic Highlands: Humanities Press, 1975.

KUHN, T. The Structure of Scientific Revolutions. 2.ed. Chicago: University of Chicago Press, 1970.

Objectivity, Value Judgement and Theory Choice. In: The Essential Tension. Chicago: University of Chicago Press, 1977.

The Presence of Past Science. London: The Shearman Memorial Lectures, University College, nov. 1987. (inédito).

LACEY, H. Constraints upon acceptable theories: Chomsky's analogy between language acquisiton and theory formation. Pacific Philosophical Quarterly, n. 65, p.166-78, 1984. 
The Rationality of Science. In: MARGOLIS, J., KRAUZ, M. e BURIAN, R. (Org.) Rationality, Relativism and the Human Sciences. Dordrecht: Nijhoff, 1986.

The Dialectic of Science and Advanced Technology: An Alternative? In: Democracy and Nature, 1997a. (no prelo).

The constitutive values of science. Principia, n.1, 1997b. (no prelo).

. Scientific Understanding and the Control of Nature. In: . Science and Education, 1998. (no prelo).

LACEY, H., SCHWARTZ, B. Behaviorism, intentionality and socio-historical structure. Behaviorism, n.14, p.193-210, 1986.

MACINTYRE, A. Epistemological crises, dramatic narrative and the philosophy of science. The Monist, n.60, p.453-72, 1977.

PUTNAM, H. Representation and Reality. Cambridge: The MIT Press, 1988.

TAYLOR, C. The Explanation of Behavior. London: Routledge and Kegan Paul, 1964.

Understanding in human science. The Review of Metaphysics, n.34, p.24-38, 47-55, 1980.

Understanding in the Geisteswissenschaften. In: HOLZMANN, S., LEICH, C. (Org.). Wittgenstein: To Follow a Rule. London: Routledge and Kegan Paul, 1981.

Human Agency and Language. Cambridge: Cambridge University Press, 1985a.

Philosophy and the Human Sciences. Cambridge: Cambridge University Press, $1985 b$. 